\title{
Sins of Omission
}

\section{Getting Too Little Medical Care May be the Greatest Threat to Patient Safety}

Rodney A. Hayward, MD, ${ }^{1,2}$ Steven M. Asch, MD, MPH, ${ }^{3}$ Mary M. Hogan, PhD, RN, ${ }^{7}$ Timothy P. Hofer, MD, MSc, ${ }^{1,2}$ Eve A. Kerr, MD, MPH 1,2

'Veterans Affairs Health Services Research \& Development Center of Excellence, Ann Arbor, Mich, USA; ${ }^{2}$ Department of Internal Medicine, University of Michigan, Ann Arbor, Mich, USA; ${ }^{3}$ Veterans Affairs Greater Los Angeles Health Care System and the Division of General Internal Medicine, David Geffen School of Medicine at UCLA, Los Angeles CA, and the Rand Health Program,

Santa Monica, Calif, USA.

BACKGROUND: Little is known about the relative incidence of serious errors of omission versus errors of commission.

OBJECTIVE: To identify the most common substantive medical errors identified by medical record review.

DESIGN: Retrospective cohort study.

SETTING: Twelve Veterans Affairs health care systems in 2 regions.

PARTICIPANTS: Stratified random sample of 621 patients receiving care over a 2-year period.

MAIN OUTCOME MEASURE: Classification of reported quality problems.

METHODS: Trained physicians reviewed the full inpatient and outpatient record and described quality problems, which were then classified as errors of omission versus commission.

RESULTS: Eighty-two percent of patients had at least 1 error reported over a 13-month period. The average number of errors reported per case was 4.7 (95\% confidence intervals [CI]: 4.4, 5.0). Overall, 95.7\% (95\% CI: $94.9 \%, 96.4 \%$ ) of errors were identified as being problems with underuse. Inadequate care for people with chronic illnesses was particularly common. Among errors of omission, obtaining insufficient information from histories and physicals (25.3\%), inadequacies in diagnostic testing (33.9\%), and patients not receiving needed medications $(20.7 \%)$ were all common. Out of the 2,917 errors identified, only 27 were rated as being highly serious, and 26 (96\%) of these were errors of omission.

CONCLUSIONS: While preventing iatrogenic injury resulting from medical errors is a critically important part of quality improvement, we found that the overwhelming majority of substantive medical errors identifiable from the medical record were related to people getting too little medical care, especially for those with chronic medical conditions.

KEY WORDS: quality of care; adverse events; patient safety; medical errors

DOI: $10.1111 /$ j.1525-1497.2005.0152.x

J GEN INTERN MED 2005; 20:686-691.

$\mathrm{P}$ eople appear to have a natural tendency to be much more disturbed by injury caused by acts of commission compared with injury caused by acts of omission, a phenomenon often referred to as "omission bias." ${ }^{1-4}$ For example, people tend to view a death resulting from a vaccine as much worse than a death resulting from not getting vaccinated. ${ }^{5,6}$ Perhaps this psychologic phenomenon, in part, underlies why the patient safety movement has so strikingly caught the attention of the public and media. ${ }^{7-12}$ Patient safety, with its emphasis on iatrogenic injury resulting from medical errors, ${ }^{7-12}$ has garnered widespread attention that greatly exceeds that generat-

Address correspondence and requests for reprint to Dr. Hayward: P.O. Box 130170, Ann Arbor, MI 48113-0170 (e-mail: rhayward@umich.edu). ed by traditional, long-standing discussions of quality of care, with its emphasis on optimizing care and outcomes. ${ }^{13-15}$

Although iatrogenic harm is always distressing, research to date suggests that the majority of such injuries are not preventable, but instead appear to result from inherent risks and limitations of medical care. ${ }^{16-20}$ In addition, the last 15 to 20 years have witnessed an explosion of valuable medical interventions (e.g., improvements in care for heart disease, HIV, diabetes, depression, hypertension, cancer prevention, etc.), ${ }^{15}$ and virtually all of these valuable interventions carry a measurable risk of iatrogenic adverse events even when provided under optimal circumstances. Therefore, although the risk of iatrogenic harm resulting from misapplications or mistakes in using the ever-growing number of medical treatments (errors of commission) has increased, so has the potential to cause serious injury and death from inadequate treatment (errors of omission) ${ }^{15,21-23}$ (see Fig. 1 and Table 1).

Although scholarly work on patient safety clearly includes an appreciation for both errors of omission and commission, discussions of safety problems, especially those aimed at the general public, have overwhelmingly highlighted preventable iatrogenic injury. ${ }^{7-12,18}$ Even in the scholarly patient safety literature, little attention has been given to the relative incidence of errors of omission versus commission. ${ }^{7-12}$ We can find no rigorous peer evaluations of the relative number of major errors of omission versus errors of commission in a representative sample that evaluated both inpatient and outpatient care. Therefore, we conducted a systematic longitudinal review of medical records to examine this issue.

\section{METHODS}

\section{Study Sample and Data Collection}

A stratified random sample of patients who had at least 2 outpatient primary care visits in each of 2 years was drawn from 12 Department of Veterans Affairs (VA) health care systems in 2 regional health care networks (Midwest and Western U.S.) that care for over 400,000 people annually. We oversampled 2 chronic medical conditions (diabetes and COPD) to obtain a minimum of 175 cases for each condition. We reviewed 621 cases, with $10 \%$ undergoing blinded, independent duplicate reviews to determine inter-rater reliability. We requested all records for each patient for a 2-year time period, inpatient and outpatient, but evaluation of quality was limited to a 13-month period.

Received for publication January 5, 2005

and in revised form February 22, 2005

Accepted for publication March 15, 2005 


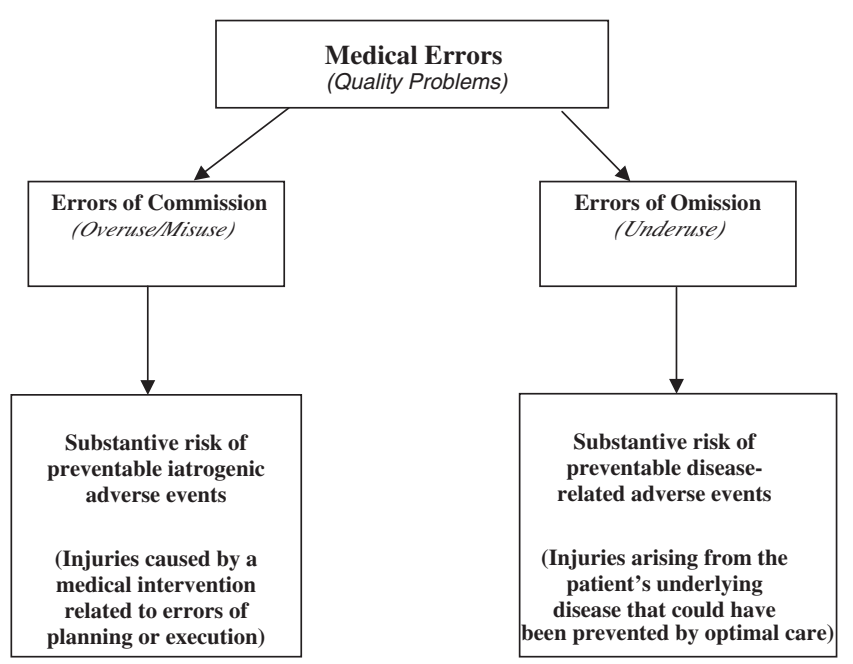

FIGURE 1. Errors of commission and errors of omission.

\section{Review Process}

Reviewers were required to be board-certified Internists with current or recent outpatient and inpatient experience as well as being conversant with the principles of evidence-based medicine. For each condition evaluated, reviewers assessed the quality of care related to diagnosis and assessment of the condition's initial presentation, the assessment and monitoring of the course of the condition, the treatment of signs or symptoms, exacerbations or complications, and follow-up. They then provided a rating of the quality of care on a 6-point scale (ranging from "very good" to "very poor"). The structured review process specifically cued them to consider the importance of any overuse, underuse, or misuse quality problems, and reviewers were warned against hindsight bias. ${ }^{22-25}$ Finally, for any care that they rated as "borderline poor," "poor," or "very poor," the reviewers wrote a description of the quality problem/error.

Reviewers were able to scan available records for the 11 months prior to the study period, but their review was restricted to rating the care provided during the 13-month study period (September 1, 1998 to September 30, 1999). The interrater reliability (IRR) for the implicit assessments of overall quality varied for different conditions and for different aspects of care but was consistently as good or better than those reported for other implicit review tools (intra-class correlation ranged from 0.16 to 0.46$).{ }^{19,26,27}$

\section{Design and Analysis of the Classification of Errors}

After reviewing previously proposed classification systems, ${ }^{7,15,17,20,28-31}$ we chose 3 overarching domains for classifying errors: (1) overuse/underuse/misuse, (2) care function (i.e., diagnosis, treatment), and (3) care modality (i.e., history, physical exam, laboratory test, medication). Pilot testing found that reviewers' verbatim descriptions could be easily divided into errors of commission versus omission, but that it was often difficult or impossible to distinguish between misuse and overuse based on the reviewers' verbatim comments. Therefore, we limited this assessment to underuse versus overuse/ misuse.

Two physician reviewers not involved in the original reviews independently classified discrete error descriptions using the previously described taxonomy (see Appendix, available online). Reviewers were also asked to denote errors that they felt were particularly serious (defined by the degree to which the error put the patient at risk of serious injury). ${ }^{23}$ When the

Table 1. Glossary: Terminology Can Vary Substantially in This Field

\begin{tabular}{|c|c|}
\hline Term & Definition \\
\hline Medical error & $\begin{array}{l}\text { An act of commission or omission that substantively increases the risk of a medical adverse event. Errors } \\
\text { can result from the failure of a planned action to be completed as intended (i.e., a mishap or error of } \\
\text { execution) or the use of a wrong plan to achieve an aim (i.e., an error of planning). }\end{array}$ \\
\hline Quality problem, or poor quality & (See Medical error) \\
\hline Error of commission & $\begin{array}{l}\text { A medical error resulting in an inappropriate increased risk of iatrogenic adverse event(s) from receiving too } \\
\text { much or hazardous treatment (overuse or misuse). Errors of commission include quality problems such } \\
\text { as excessive doses of medications, treatments that are contraindicated, inadvertently giving the wrong } \\
\text { medication, or iatrogenic risk resulting from unneeded interventions. }\end{array}$ \\
\hline Overuse/misuse & $\begin{array}{l}\text { When a test or treatment is offered or provided, intentionally or unintentionally, that has iatrogenic risks } \\
\text { that outweigh its potential benefits, for example, performing a surgery that was not indicated, giving an } \\
\text { inappropriately high dose of a medication, or giving a patient who needs an antibiotic amoxicillin } \\
\text { despite them having a known penicillin allergy. }\end{array}$ \\
\hline Error of omission & $\begin{array}{l}\text { A medical error resulting in an inappropriate increased risk of disease-related adverse event(s) resulting } \\
\text { from receiving too little treatment (underuse). Errors of omission include quality problems such as } \\
\text { delays in diagnosis, subtherapeutic doses of medications, and failure to provide indicated treatments. }\end{array}$ \\
\hline Underuse & $\begin{array}{l}\text { When there is a failure to recommend or provide a beneficial procedure, therapy, or diagnostic test, } \\
\text { intentionally or unintentionally, for example, not providing medication to control hypertension for a } \\
\text { patient who could benefit from treatment or a delay in treatment caused by a delay in making the } \\
\text { correct diagnosis. }\end{array}$ \\
\hline Medical adverse event & $\begin{array}{l}\text { A medical injury or complication. Adverse events can occur despite appropriate care (such as recognized } \\
\text { complications of an intervention or resulting from the person's underlying disease) or can be caused by } \\
\text { errors of omission or commission. }\end{array}$ \\
\hline Iatrogenic medical adverse event & $\begin{array}{l}\text { An adverse event caused by a medical intervention. Iatrogenic adverse events can be caused by appropriate } \\
\text { care (recognized risks of treatment such as known complications of procedures or side-effects of } \\
\text { medications) or caused by errors of commission. }\end{array}$ \\
\hline Disease-related adverse event & $\begin{array}{l}\text { An adverse event resulting from a medical condition (i.e., a disease complication). Disease-related adverse } \\
\text { events can occur despite appropriate care or can be caused by errors of omission (resulting from } \\
\text { underuse of indicated medical interventions). }\end{array}$ \\
\hline
\end{tabular}


blinded, independent ratings of the 2 reviewers' disagreed with each other (1,038 [11.7\%] out of 8,838 total classification decisions on function, modality, and care problem made on 2,946 discrete error descriptions), a third reviewer (M. H.) reviewed the verbatim response. Her rating settled the tie when she felt that one reviewer's assessment was clearly correct $(n=886)$. In a few instances $(n=16)$, she felt that neither reviewer answer was correct. In such cases, a group review was conducted (usually resulting in a classification of "unclear/insufficient information"). If she felt that either answer was reasonable (i.e., difficult or close calls) $(n=136)$, the disagreement between reviewers was settled by random assignment (to prevent the third reviewer from introducing bias by systematically deciding "close calls"). ${ }^{32}$ Some verbatim descriptions $(n=29)$ did not identify a medical error and were dropped, leaving 2,917 items for analysis. The reliability for classifying verbatim responses was high: overuse/misuse versus underuse $(\kappa=0.75)$, care function $(\kappa=0.79)$, and core modality $(\kappa=0.81)$.

\section{Data Analysis}

Analyses primarily involved descriptive statistics. After classifying verbatim descriptions of reviewers' comments, as described above, we calculated the frequencies, percentages, and $95 \%$ confidence intervals (CI) for the various types of errors, correcting for clustering (by patient and site) and design effects (over-sampling) using the Stata 8.0 statistical package (StataCorp, College Station, TX).

\section{RESULTS}

Of the 621 cases, $82 \%$ had at least some care that was considered "borderline poor" or worse (Table 2), with an average of 4.7 (95\% CI, 4.4, 5.0) discrete errors identified per case. Of the specific conditions, diabetes care had the highest reported error rate ( 1.7 per diabetes case) and acute conditions had the lowest ( 0.6 errors per acute condition case). Of errors that could be classified (36 descriptions were rated "unclear/not classifiable"), 95.7\% (95\% CI, 94.9\% to 96.4\%) were classified as underuse and $4.3 \%$ (95\% CI, $3.6 \%$ to $5.1 \%$ ) as overuse/ misuse. For the 4 chronic conditions, $4 \%$ of errors were caused by overuse/misuse, whereas $14 \%$ of errors for acute condition care were caused by overuse/misuse. However, this higher relative frequency of overuse problems was not caused by a higher absolute frequency of overuse errors for acute condition care, but rather, the care for acute conditions had a much lower frequency of underuse errors. For example, the 621 cases averaged 0.13 overuse/misuse errors per case and 2.85 underuse errors per case related to chronic disease care, compared with 0.09 overuse/misuse errors per case and 0.54 underuse errors per case for acute care in the 409 cases with an acute condition.

With regard to errors of omission, over half the problems identified were classified as related to diagnosis and monitoring, with about one third related to treatment (Table 3). Obtaining insufficient information from histories and physicals (25.3\%), inadequacies in diagnostic testing (33.9\%), and patient not receiving needed medications $(20.7 \%)$ were all commonly reported problems. Examples of insufficient information from histories and physicals include a patient with facial weakness without further documented neurologic examination and a patient with lower extremity edema and no cardiac examination recorded. Examples of inadequacies in diagnostic testing include a patient with known coronary artery disease and new onset chest pain who received no stress testing, and a patient who presented with night sweats but received no chest $\mathrm{x}$-ray or ppd. Some examples of not providing needed medications include a patient with a previous lacunar stroke who was not on an anti-platelet agent, and a patient with type 2 diabetes who had no medication changes despite marked and repeated elevations of blood pressure. Additional examples can be found in the Appendix.

We were concerned that although underuse errors may be much more common overall, perhaps overuse/misuse errors make up a disproportionate percentage of the most serious medical errors. However, this was not the case. The reviewers only rated 27 of the 2,917 identified errors as being particularly serious, and only 1 of these errors (3.7\%) was an error of commission, which involved giving simvastatin to a patient with a reported allergy to statins. Of the remaining 26 major errors, multiple instances were reported for inadequate assessment for or treatment of coronary artery disease $(n=14)$, marked hypertension $(n=3)$, thrombotic risk $(n=3)$, cardiac arrhythmias $(n=2)$, and hyperkalemia $(n=2)$.

\section{CONCLUSIONS}

A dedication to safety is a critically important responsibility of any industry. ${ }^{7}$ However, when providing air transportation or

Table 2. Classification of Medical Errors Identified by Physician Implicit Review

\begin{tabular}{|c|c|c|c|c|c|c|}
\hline & $\begin{array}{l}\text { \# Cases with } \\
\text { This Condition }\end{array}$ & $\begin{array}{l}\text { Chart had One } \\
\text { or More Aspects of } \\
\text { Care Rated as } \\
\text { Borderline/Poor } \\
\text { Frequency } \\
(\%)\end{array}$ & $\begin{array}{c}\text { Frequency of } \\
\text { Quality Problems } \\
\text { Frequency (Errors } \\
\text { per Case) }\end{array}$ & $\begin{array}{l}\text { Underuse (Errors } \\
\text { of Omission) } \\
\text { Frequency (\% of } \\
\text { Classifiable Errors) }\end{array}$ & $\begin{array}{l}\text { Overuse/Misuse } \\
\text { (Errors of } \\
\text { Commission) } \\
\text { Frequency (\% of } \\
\text { Classifiable Errors) }\end{array}$ & $\begin{array}{l}\text { Unclear Whether } \\
\text { Error was Underuse } \\
\text { or Overuse } \\
\text { Frequency }\end{array}$ \\
\hline Hypertension & 500 & 246 (49\%) & $464(0.9)$ & $429(94.5)$ & $25(5.5)$ & 10 \\
\hline COPD & 167 & 90 (54\%) & $227(1.4)$ & $216(96.4)$ & $8(3.6)$ & 3 \\
\hline Diabetes & 258 & $149(58 \%)$ & $427(1.7)$ & $411(97.9)$ & $9(2.1)$ & 7 \\
\hline Other chronic diseases & 614 & $294(48 \%)$ & $758(1.2)$ & $712(95.2)$ & $36(4.8)$ & 10 \\
\hline Acute conditions & 409 & $142(35 \%)$ & $259(0.6)$ & $221(86.0)$ & $36(14.0)$ & 2 \\
\hline Prevention & 621 & 357 (57\%) & $782(1.3)$ & 767 (98.6) & $11(1.4)$ & 4 \\
\hline Overall [95\% CI] & 621 & $\begin{array}{c}512(82 \%) \\
{[79 \%, 86 \%]}\end{array}$ & $\begin{array}{c}2,917(4.7) \\
{[4.4,5.0]}\end{array}$ & $\begin{array}{l}2,756(95.7) \\
{[94.9,96.4]}\end{array}$ & $\begin{array}{c}125(4.3) \\
{[3.6,5.1]}\end{array}$ & 36 \\
\hline
\end{tabular}

CI, confidence interval. 
Table 3. Attributes of Errors of Omission

\begin{tabular}{lccc}
\hline \hline Delays or Insufficiencies in Care & Frequency & Percent (\% of Classifiable Errors) & 95\% Confidence Intervals \\
\hline Care function & $N=2,756$ & & 53.5 \\
$\quad$ Diagnosis/assessment/monitoring & 1471 & 33.4 & $51.5,55.8$ \\
Treatment & 919 & 13.1 & $30.8,35.9$ \\
Prevention/screening & 360 & - & $10.6,15.6$ \\
Unclear/not specified & 6 & 25.3 & $22.9,27.7$ \\
Clinical modality & 523 & 33.9 & $31.5,36.3$ \\
History and exam & 701 & 20.7 & $17.7,23.6$ \\
Diagnostic testing & 427 & 9.8 & $7.1,12.6$ \\
Medications & 203 & 5.3 & $3.9,6.6$ \\
Immunizations & 109 & 0.6 & $0.3,0.9$ \\
Education/counseling & 13 & 4.4 & $3.2,5.4$ \\
Surgery/procedures/therapy & 90 & - & \\
Visit interval/referral/admission & 690 & & \\
Unclear/not specified & & \\
\hline
\end{tabular}

selling kitchen appliances, consumer safety is generally limited to considerations of the risks related to using the service or product, whereas, improving consumer safety in medicine requires assessing, and often balancing, the potential harm of inappropriate non-intervention (errors of omission), as well as inappropriate or unsafe intervention (errors of commission) (Fig. 1). In this way, medicine has more in common with the military or law enforcement, in that the risks of friendly fire and intervening too early or too much must be weighed against the risks of enemy fire and intervening too slowly or insufficiently.

Although iatrogenic adverse events are sometimes talked about as if they are synonymous with medical errors, increasing a patient's risk of iatrogenic adverse events will often be the right thing to do. ${ }^{21-23}$ For example, underuse of thrombolytics, anti-platelet agents, and anticoagulants are common causes of preventable morbidity and mortality. ${ }^{15,33,34}$ However, appropriate use of these medications clearly and substantially increases iatrogenic adverse events even when done optimally. Of course, misapplications or mishaps in the use of medical interventions can result in iatrogenic injuries that are truly appalling. ${ }^{7,12}$ Therefore, discussions and considerations of adverse events, patient safety, and medical errors must always consider the appropriateness of medical intervention at the time the decision was made, ${ }^{23,35}$ to try and avoid secondguessing influenced by hindsight and omission bias. ${ }^{25}$

To our knowledge, our study is the first systematic examination of the balance between substantive errors of omission versus commission using a detailed peer evaluation of both the inpatient and outpatient medical record. We found that the vast majority of medical errors noted by trained reviewers were related to errors of omission. This finding was consistent across a variety of conditions and was equally true when limiting review to those errors that were felt to be the most serious. Many experts have decried the inadequacies of our health care system for taking care of those with chronic illnesses, ${ }^{15,36}$ and insufficient care for people with chronic illness was particularly prominent in our study. For example, there were over 3 times more substantive errors of omission related to diabetes care than there were errors of commission related to all conditions combined in the entire patient sample.

Some previous research has examined errors of omission and commission in the inpatient setting ${ }^{17,20,29}$ or using explicit review criteria. ${ }^{31,37}$ Although anecdotes of mishaps causing iatrogenic complications tend to be highlighted in most discus- sions of medical errors, a careful reading of past studies reveals that our results are not that dissimilar from results found in inpatient settings. Evaluations of inpatient errors have consistently found that at least half of major adverse events reportedly resulting from medical errors were related to underuse. ${ }^{17,20,29}$ For example, the Utah-Colorado Study (UT$\mathrm{COS}$ ) found that for inpatient care, excluding adverse events related to neonatal care and patient falls, permanent disability and death were almost 3 times more likely to be caused by underuse errors than overuse/misuse errors. ${ }^{17}$ Still, our study found an even greater preponderance of underuse errors than previous studies, and we believe that there are several potential reasons for this finding. First, most previous studies mainly or solely examined errors in hospital care, where errors of commission might be relatively more common. ${ }^{17,20,29}$ Second, most previous studies sampled adverse events and then worked backward to find errors. Such retrospective, unblinded reviews may overestimate errors of commission because even experts are highly subject to hindsight and omission bias. ${ }^{1-5,24,38}$ On the other hand, it also seems likely that the occurrence of adverse events might increase documentation of otherwise undetectable overuse/misuse errors. Third, the number of errors of omission may have increased since the studies conducted in the 1980s and the early 1990s. As the number of treatments known to produce benefit has increased and cost containment efforts have favored less use, the percentage of errors resulting from undertreatment may also have increased. For example, using an explicit review instrument, McGlynn et al. ${ }^{31}$ found that patients failed to receive nearly $50 \%$ of indicated care.

Our findings are limited to 12 VA health care facilities, and therefore our estimates of underuse versus overuse/misuse should not be overly generalized to other settings. However, we think it likely that the general finding is not limited to VA facilities. Indeed, both overall quality and receipt of recommended care have generally been reported to be as good or better in VA than in other sectors of the US health care system. ${ }^{39-41}$ A more major and inherent limitation of our study is its reliance on the medical record. Medical errors are frequently not identifiable from the medical record; ${ }^{18,42,43}$ however, most of the albeit limited information on this topic has not found major differences in the types of errors found in the medical record versus patient or medical personnel reports. ${ }^{18,42,44}$ In addition, the VA medical record system has been found to be fairly reliable in accessing quality. ${ }^{45}$ Still, it 
may be that overuse/misuse errors are much more difficult to detect by medical record review than underuse errors and quality related to technical skill (such as how well a procedure or surgery is performed) is virtually impossible to glean from the medical record. Therefore, our results must be qualified as only pertaining to the types of medical errors that can be detected from medical record review.

What are the implications of our findings? These results clearly show that the attention given to patient safety is well deserved, but also suggests that some portrayals of the nature of the problem may be misleading. A detailed understanding of the overall incidence and importance of errors of omission versus commission can be critical when trying to improve the effectiveness, efficiency, and safety of health care. ${ }^{23,46-48}$ Many of the system solutions being pursued by patient safety and human factors experts ${ }^{7,15}$ clearly have the promise of substantially reducing both types of errors and our findings create a stronger case for such safety systems. For example, improving communication between providers, enhancing information availability, and the use of electronic alerts, reminders, and order entry ${ }^{7,15,22}$ all have direct relevance to reducing errors of commission and errors of omission. However, we risk overlooking important opportunities for designing these systems to optimally improve patient safety if we fail to understand the incidence and full importance of errors of omission.

Further, some proposed safety interventions either directly or indirectly present risks of increasing underuse (such as redundancy systems, compulsory order renewals, mandatory referrals, drug interaction alerts, and pre-authorization). In such instances, our appropriate abhorrence for iatrogenic injuries can lead us to bad decisions if we fail to reflect upon the incidence and relative importance of errors of omission versus commission for the specific situation under consideration. This is another instance in which health care can learn from safety efforts in other industries. ${ }^{49-52}$ For example, when 4 people died in a British rail accident in 2000 , the rail authority reduced maximum allowable rail speeds, which was felt to subsequently contribute to substantial reductions in rail travel-resulting in increased auto deaths, economic losses, and pollution. ${ }^{52}$ Similarly, an intemperate response to tragic iatrogenic blunders can do more harm than good or result in the diversion of scarce resources from more important, and fixable, health care problems. For example, tunnel vision in trying to eliminate drug-drug interactions could lead to "safety systems" that inadvertently increase patient injury. One of us (R. H.) recently received a pharmacy alert warning that one of his patients was on both aspirin and lisinopril (which have a known drug-drug interaction). However, the risk of aspirinACE-inhibitor interactions (though possible with high doses of salicylates) is trivial compared to the thousands of major adverse events and deaths occurring each year resulting from underuse of these medications. ${ }^{15,34,53-55}$ Even very small reductions in the use of these life-saving medications in response to such wellmeaning alerts would far outweigh any potential benefits.

In summary, we found that over $95 \%$ of medical errors identified in a review of patients' medical records were caused by patients receiving too little medical care. These results are limited to errors that can be detected by medical record review; nonetheless, they clearly demonstrate that patient safety and quality improvement efforts must carefully reflect upon transgressions related to those things we do and those things we fail to do. Although deserved attention has been directed to iatro- genic harm resulting from medical blunders, research to date suggests that underuse of needed treatments is probably the greatest risk to patient safety.

The work was supported by the Department of Veterans Affairs Health Services Research \& Development (HSR\&D) Grant IIR 98-103, with additional support from the VA Quality Enhancement Research Initiative (HSR\&D DIB \#98-001) and the Michigan Diabetes Research \& Training Center (NIDDK P60-972573). Drs. Kerr and Asch were supported by Career Development Awards from the HSR\&D Office of the Department of Veterans Affairs.

\section{REFERENCES}

1. Tversky A, Kahneman D. Loss aversion in riskless choice: a referencedependent model. Q J Econ. 1991;106:1039-61.

2. Kahneman D, Tversky A. Prospect theory: an analysis of decision under risk. Econometrica. 1979;ALVII:263-91.

3. Kahneman D, Tversky A. The simulation heuristic. In: Judgment Under Uncertainty: Heuristics and Biases. New York: Cambridge University Press; 1982.

4. Spranca M, Minsk E, Baron J. Omission and commission in judgement and choice. J Exp Soc Psychol. 1991;27:76-105.

5. Ritov I, Baron J. Reluctance to vaccinate: omission bias and ambiguity. J Behav Decis Making. 1990;3:263-77.

6. Asch DA, Baron J, Hershey JC, et al. Omission bias and pertussis vaccination. Med Decis Making. 1994;14:118-23.

7. Institute of Medicine. To Error is Human: Building a Safer Health System. Washington, DC: National Academy Press; 1999.

8. Millenson ML. Pushing the profession: how the news media turned patient safety into a priority. Qual Safety Health Care. 2002;1 1:56-63.

9. Dentzer S. Media mistakes in coverage of the Institute of Medicine's error report. Eff Clin Pract. 2000;3:305-8.

10. American Iatrogenic Association Library. Information that improves understanding of medical error, philosphy, and practice. Accessed February 21, 2004: http://www.iatrogenic.org/library/mederrorlib.html

11. The Leapfrog Group. Patient safety. Accessed February 21, 2004: http://www.leapfroggroup.org/safety.htm

12. Wachter RM, Shojania KG. Internal Bleeding: The Truth Behind America's Terrifying Epidemic of Medical Mistakes. New York: Rugged Land, LLC; 2004.

13. Brook RH. Quality of care: do we care? Ann Intern Med. 1991;115:48690.

14. Chassin MR, Galvin RW. The urgent need to improve health care quality. Institute of Medicine National Roundtable on Health Care Guality. JAMA. 1998;280:1000-5.

15. Committee on Quality of Health Care in America: Institute of Medicine. Crossing the Quality Chasm: A New Health System for the 21st Century. Washington, DC: National Academy Press.

16. Brennan TA, Leape LL, Laird NM, et al. Incidence of adverse events and negligence in hospitalized patients. N Engl J Med. 1991;324:370-6.

17. Thomas EJ, Studdert DM, Burstin HR, et al. Incidence and types of adverse events and negligent care in Utah and Colorado. Med Care. 2000;38:261-71.

18. Gandhi TK, Weingart SN, Borus J, et al. Adverse drug events in ambulatory care. N Engl J Med. 2003;348:1556-64.

19. Hayward RA, Hofer TP. Estimating hospital deaths due to medical errors: preventability is in the eye of the reviewer. JAMA. 2001;286: 415-20.

20. Leape LL, Brennan TA, Laird N, et al. The nature of adverse events in hospitalized patients: results of the Harvard Medical Practice Study II. N Engl J Med. 1991;324:377-84.

21. Fisher ES, Welch HG. Is this issue a mistake? Eff Clin Pract. 2000; 3:290-3.

22. Hofer TP, Hayward RA. Are bad outcomes from questionable clinical decisions preventable medical errors?: a case of cascade iatrogenesis. Ann Intern Med. 2002;137:327-33.

23. Hofer TP, Kerr EA, Hayward RA. What is an error? Eff Clin Pract. 2000;3:261-9.

24. Caplan RA, Posner KL, Cheney FW. Effect of outcome on physician judgments of appropriateness of care. JAMA. 1991;265:1957-60 
25. Thompson SC, Armstrong W, Thomas C. Illusions of control, underestimations, and accuracy: a control heuristic explanation. Psychol Bull. 1998;123:143-61.

26. Hofer TP, Asch SM, Hayward RA, et al. Profiling quality of care: is there a role for peer review? BMC Health Serv Res. 2004;4:9

27. Goldman RL. The reliability of peer assessments of quality of care. JAMA. 1992;267:958-60.

28. Dovey SM, Meyers DS, Phillips RL Jr, et al. A preliminary taxonomy of medical errors in family practice. Qual Safety Health Care. 2002;11: 233-8.

29. Bates DW, Cullen DJ, Laird N, et al. Incidence of adverse drug events and potential adverse drug events. Implications for prevention. ADE prevention study group. JAMA. 1995;274:29-34.

30. Elder NC, Dovey SM. Classification of medical errors and preventable adverse events in primary care: a synthesis of the literature. J Fam Pract. 2002;51:927-32.

31. McGlynn EA, Asch SM, Adams J, et al. The quality of health care delivered to adults in the United States. N Engl J Med. 2003;348: 2635-45.

32. Hofer TP, Bernstein SJ, DeMonner S, Hayward RA. Discussion between reviewers does not improve reliability of peer review of hospital quality. Med Care. 2000;38:152-61.

33. Kent DM, Hayward RA, Griffith JL, et al. An independently derived and validated predictive model for selecting patients with myocardial infarction who are likely to benefit from tissue plasminogen activator compared with streptokinase. Am J Med. 2002;113:104-11.

34. Hayward RA. Diabetes care priorities: preventing cardiovascular complications. Pract Matters. 2000;5:1-6.

35. Brook RH. Appropriateness: the next frontier. BMJ. 1994;308:218-9.

36. Glasgow RE, Hiss RG, Anderson RM, et al. Report of the health care delivery work group: behavioral research related to the establishment of a chronic disease model for diabetes care. Diabetes Care. 2001;24: 124-30.

37. Wenger NS, Solomon DH, Roth CP, et al. The quality of medical care provided to vulnerable community-dwelling older patients. Ann Intern Med. 2003 Nov 4;139:740-7.

38. Brennan TA. The Institute of Medicine Report on medical errors - could it do harm? N Engl J Med. 2000;342:1123-5.

39. Jha AK, Perlin JB, Kizer KW, Dudley RA. Effect of the transformation of the Veterans Affairs Health Care System on the quality of care. N Engl J Med. 2003;348:2218-27.

\section{Supplementary Material}

The following supplementary material is available for this article online:

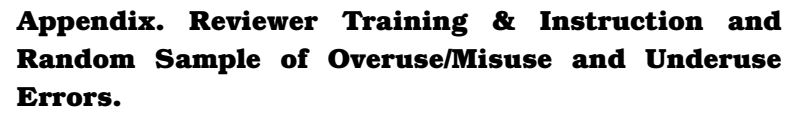

Appendix. Reviewer Training \& Instruction and Random Sample of Overuse/Misuse and Underuse Errors.

40. Asch SM, McGlynn EA, Hogan MM, et al. Comparison of quality of care for patients in the Veterans Health Administration and patients in a national sample. Ann Intern Med. 2004; 141:938-45.

41. Kerr EA, Gerzoff RB, Krein SL, et al. A comparison of diabetes care quality in VA and commercial managed care: the TRIAD study. Ann Intern Med. 2004;141:272-81.

42. O'Neil AC, Petersen LA, Cook EF, Bates DW, Lee TH, Brennan TA Physician reporting compared with medical-record review to identify adverse medical events. Ann Intern Med. 1993;119:370-6.

43. Bates DW, Leape LL, Petrycki S. Incidence and preventability of adverse drug events in hospitalized adults. J Gen Intern Med. 1993;8:289-94.

44. Brennan TA, Localio AR, Leape LL, et al. Identification of adverse events occurring during hospitalization. A cross-sectional study of litigation, quality assurance, and medical records at two teaching hospitals. Ann Intern Med. 1990;112:221-6.

45. Luck J, Peabody JW, Dresselhaus TR, Lee M, Glassman P. How well does chart abstraction measure quality? A prospective comparison of standardized patients with the medical record. Am J Med. 2000;108:642-9.

46. Donabedian A. Quality, cost: choices and responsibilities. Inquiry. 1988;25:90-9.

47. Donabedian A. The Definition of Quality and Approaches to its Assessment. Ann Arbor, Mich: Health Administration Press; 1980.

48. Woolf SH. Patient safety is not enough: targeting quality improvements to optimize the health of the population. Ann Intern Med. 2004;140:33-6.

49. Reason J. Human error: models and management. BMJ. 2000;320: 768-70.

50. Reason JT. Managing the Risks of Organizational Accidents. Burlington, Vt: Ashgate Publishing.

51. Perrow C. Normal Accidents Living with High-risk Technologies. 2nd ed. Princeton, NJ: Princeton University Press; 1999.

52. Something must (not) be done. The Economist. September 11, 2003

53. Vijan S, Hayward RA. Treatment of hypertension in type 2 diabetes mellitus: blood pressure goals, choice of agents, and setting priorities in diabetes care. Ann Intern Med. 2003;138:593-602.

54. Rosen AB, Karter AJ, Liu JY, Selby JV, Schneider EC. Use of angiotensin-converting enzyme inhibitors and angiotensin receptor blockers in high-risk clinical and ethnic groups with diabetes. J Gen Int Med. 2004; 19:669-75.

55. Yarnall KS, Pollak KI, Ostbye T, Krause KM, Michener JL. Primary care: is there enough time for prevention? Am J Public Health. 2003;93: 635-41. 